$$
\begin{array}{r}
\text { DOSSIE } \\
\text { MARCELO MARQUES: } \\
\text { pensador, professor, amigo }
\end{array}
$$





\title{
A POIESIS DO CAMINHO FILOSÓFICO DE MARCELO MARQUES
}

\author{
THE ROUTE OF MARCELO MARQUES
}

\begin{abstract}
Miriam C. D. Peixoto* * Professora
Associada,

Departamento

N

ós escolhemos como caminho para apresentar este dossiê em homenagem ao nosso colega e amigo, o professor Marcelo Marques, o exame de passagens de dois de seus textos, representativos do início e do fim de sua atividade intelectual. Neles encontramos os temas que bem sintetizam as preocupações e reflexões que o acompanharam ao longo de todo seu percurso de Filosofia, Universidade Federal de Minas Gerais. mcdpeixotobh@ gmail.com acadêmico, e constituem, aos nossos olhos, o ponto de inflexão a partir do qual ganhou forma o seu itinerário filosófico: por um lado, o livro em que apresenta a sua dissertação de mestrado, $O$ Caminho poético de Parmênides, ${ }^{1}$ por outro, o memorial que apresentou como requisito para o concurso de promoção à classe de professor titular da Universidade Federal de Minas Gerais. A dissertação de mestrado, elaborada sob a orientação da Professora Sônia Viegas, ${ }^{2}$ já prefigura o universo dos temas que constituíram seu horizonte de investigação ao longo de toda a sua trajetória de pesquisador e docente, o que se pode constatar pela leitura do memorial em que apresenta e reflete sobre o seu próprio percurso intelectual.

Como é sabido de todos aqueles que tiveram a oportunidade de conviver com o Marcelo, seja como aluno, seja como orientando ou colega, filosofia e literatura sempre estiveram profundamente entrelaçadas nos diferentes âmbitos da sua atividade acadêmica, o que

\footnotetext{
${ }^{1}$ Marques, M. P. O caminho poético de Parmênides. Coleção "Filosofia". São Paulo: Edições Loyola, 1990.

${ }^{2}$ A sua banca de defesa de dissertação de mestrado, que teve lugar em 1989, teve como membros, além da sua orientadora, Silvio Barata, professor de História da Filosofia Grega da UFMG, e os professores Henrique Cláudio de Lima Vaz (o Padre Vaz) e José Cavalcanti de Souza, estudioso e tradutor dos Pré-Socráticos e de Platão. A orientação da dissertação de mestrado de Marcelo foi a última da professora Sônia Viegas, que veio a falecer algumas semanas depois de sua defesa, aos 45 anos de idade. Sua influência no
} pensamento de Marcelo e na sua concepção de Filosofia foi decisiva.
\end{abstract}


evidencia o quanto ele fora influenciado pela Professora Sônia Viegas, de quem foi aluno e, como ele mesmo gostava de dizer, discípulo, desde os tempos do ensino médio, quando nele começou a ganhar expressão o pathos filosófico. A este propósito, ele escreveu em seu memorial: "compreendi que era possível fazer Filosofia de maneira articulada à Literatura". Quanto às razões que determinaram o seu interesse pelo poema filosófico de Parmênides como objeto para a realização de sua dissertação de mestrado, elas foram assim apresentadas por ele:

Após assistir às aulas do Prof. Hugo Amaral sobre Wittgenstein (tendo em vista, principalmente, as Investigações Filosóficas, 1953), elaborei minha primeira tentativa de projeto de Mestrado: O mito como ato de fala em Hesíodo, para mostrar toda a vitalidade e relevância da questão, sempre atual, da consciência mítica enquanto 'modo de agir pela palavra'. Mas eu também tinha sido aluno do Prof. Silvio Barata Vianna e lido sua dissertação de Mestrado, O idealismo de Parmênides de Eleia (1973), que me instigava em outra direção. Finalmente, a mediação entre minhas três frentes de interesse teórico (Literatura, Teorias da linguagem e Filosofia Antiga) foi feita, novamente, por Sônia Viegas, sob cuja orientação elaborei o projeto de Mestrado que acabei desenvolvendo e defendendo.

Seu caminho de pesquisa e de estudo se orientou em duas direções principais: aquela da reflexão sobre o tema da relação entre mito, literatura e filosofia (do qual resulta, entre outros, o texto Mito e filosofia, publicado em 1994) e aquele do problema da alteridade, da diferença, que desembocou nos últimos anos no estudo da relação entre ser e parecer. E no entrelaçar dos caminhos orientados por estes interesses, vemos aflorar outros tantos temas de predileção como, por exemplo, o da natureza do prazer e o da relação entre retórica e dialética. Em uma passagem de seu memorial, ele assim se exprimiu sobre as questões que concorreram à configuração de seu horizonte inicial de pesquisa:

A meu ver, há uma relação dinâmica e complexa entre a práxis (compreendida como vivência mítica) e o lógos (entendido como discursividade emergente, filosófica e outras), que tem como eixo decisivo a poíesis (fabricação poética). Por um lado, o interesse da pesquisa consistia em reconhecer esse dinamismo tridimensional em Parmênides e construí-lo a partir dos termos e das formulações mesmas do poema; um texto compacto, difícil, arquetípico da História da Filosofia ocidental, que comecei a frequentar humildemente, tendo em vista o fato de que me contrapunha frontalmente à perspectiva adotada pelo Prof. Barata; por outro lado, minha proposta era demasiadamente ousada, na medida em que trabalhava inspirado nas reflexões de Sônia Viegas, sobre a tensão entre a palavra poética e a palavra filosófica na filosofia contemporânea; nas suas publicações e aulas, ela ia de Hegel a Mallarmé, passando por Nietzsche e Merleau-Ponty, mergulhando, particularmente, na obra maior da literatura brasileira, O Grande Sertão: veredas de Guimarães Rosa. 
Destes anos de formação se depreende a gestação estratégica que viria a caracterizar o seu empreendimento hermenêutico na abordagem do pensamento da filosofia antiga como um todo. Marcelo dizia ter aprendido com Sônia Viegas o ofício do que chamava de "narrador-pesquisador" ou "mito-lógico", que a seu ver se encontra "na encruzilhada fundadora da filosofia ocidental", o qual consistiria, fundamentalmente em ser

... o fabricador (poietés) e teorizador de seu próprio percurso (meta-hodós), seja ele guerreiro aristocrata aqueu, desbravador eleata dos caminhos (do 'ser' e do 'não ser') ou jagunço peleando nas veredas do sertão mineiro. O relato dramático desse narrador parte da vivência bruta e imediata, trabalha reflexivamente o corpo mesmo da palavra, plasma seu poder de transposição (metaphoreîn), e tende progressivamente à tomada de consciência de diferentes possibilidades de significação do 'que é' e do 'que não é'.

Ao abraçar como objeto de pesquisa de seu mestrado um pensador como Parmênides, Marcelo estava reconhecendo o protagonismo do filósofo, espécie de divisor de águas da Filosofia Antiga (mas talvez muito mais que meramente da filosofia antiga), ponto de bifurcação das principais vias nas quais se desenvolveu a filosofia na Antiguidade. Dando curso à avaliação de intérpretes como Cleménce Ramnoux, por cuja obra ele nutria grande simpatia, Marcelo reconheceu a importância de pensadores como Heráclito e Parmênides na gênese das diferentes tradições da filosofia grega. Sobre esses dois pensadores ele escreveu em seu memorial:

... a filosofia pré-socrática se divide em dois períodos, 'antes de Heráclito’ e ‘depois de Parmênides'. Gosto dessa abordagem porque ela nos propõe o desafio de articular os dois filósofos pré-socráticos maiores, reconhecendo o quanto eles têm em comum, contra a leitura superficial, que os opõe esquematicamente. A meu ver, ambos falam e pensam a partir de um mesmo fundo de cultura, formulando caminhos e estilos filosóficos diferentes, é verdade, mas lidando cada um a seu modo, com os mesmos problemas fundamentais, dentre os quais o da relação entre movimento e repouso, a finitude do humano e o absoluto da racionalidade, compreendida enquanto algo de divino. Não se deve atribuir nem a um nem a outro as radicalizações que, hoje sabemos, são próprias de seus discípulos, seguidores ou críticos.

A consciência acerca do risco das radicalizações e generalizações na interpretação dos Antigos, e a necessidade de colocá-las sob suspeita, sempre esteve presente em sua atividade de intérprete. Tal disposição se encontra na base mesma de seu próprio empreendimento filosófico, como podemos ver nesta série de perguntas que o guiaram em sua investigação: 
Num sentido profundo, minha pesquisa é a retomada incessante do poema de Parmênides e a tentativa de compreender o percurso cultural e intelectual entre Zenão de Eleia e Platão: em que medida Zenão trai Parmênides "por excesso de fidelidade"? O que faz com que os atomistas retomem o 'ser' e o 'não ser' como átomo e vazio? Será que Zenão, com suas polêmicas, já inaugura o percurso dos sofistas? Em que medida Górgias de Leontino com seu Tratado do 'não ser' é um momento necessário na compreensão do percurso que vai do 'poema' ao 'diálogo' filosófico? O quanto Protágoras de Abdera é um interlocutor decisivo na formulação da filosofia platônica?

O espírito elêntico caracterizava a sua relação com os grandes temas da filosofia antiga e determinava a necessária mise-en-cause das interpretações correntes. Foi assim que de modo destemido encarou o estudo do poema de Parmênides, o que, segundo ele, representava um grande desafio, pois implicava se confrontar com a exaustiva produção bibliográfica já existente em torno do pensamento Eleata, o que já totalizava, no período que vai de 1573 a 1983, 591 títulos entre livros e artigos. No entanto, em lugar de desistir do exame dos versos por ele considerados "tão polêmicos e já tão suficientemente comentados", ele se deixou envolver, como ele próprio diz, "pelo fascínio que este venerável poeta-pensador ainda é capaz de exercer”. E justifica, assim, sua determinação e perseverança:

Persistimos porque, se por um lado, Parmênides nos ensina que é próprio aos caminhos humanos errar, é ele também quem mostra que vale a pena caminhar, pois há um caminho que efetivamente leva ao seu destino. $\mathrm{E}$ ainda, persistimos porque só assim estaremos dando mostra da vitalidade de seus versos que, longe de nos desviarem da busca que é a filosofia, nos incitam ainda mais a buscar. Finalmente persistimos porque acreditamos que os estudos clássicos interessam hoje a todos aqueles que, tendo sido incorporados à matriz civilizacional do ocidente europeu, reconhecem na emergência do saber entre os primeiros filósofos gregos o despontar de suas próprias consciências. (O caminho poético de Parmênides, p. 14).

Nesta justificativa, em certa medida autobiográfica na justificação de seu corajoso empreendimento, vemos esboçarem-se aquelas motivações que subsistiram em todo seu percurso acadêmico. Conjugavam-se nele o fascínio pela poesia filosófica, ou pela filosofia poética de Parmênides (e depois pela poiesis platônica), o prazer de ser um aprendiz do caminhar, a consciente humanidade da errância e do valor da polêmica, controvérsia e da refutação como ingredientes desta caminhada. E ele não se deixava intimidar pelo desafio representado pela posição de quem está entre, do pouco confortável lugar do filósofo como um ser entre a ignorância e a sabedoria, como descrevera Platão no Simpósio. Como o eros philosophos do diálogo platônico, Marcelo se entregou amorosamente e persistentemente a esta incessante busca, impregnado da convicção de que nada era mais natural a quem frequenta os antigos que este sentimento de estar sempre a caminho. 
A "tarefa" que tomou na leitura do poema de Parmênides tinha por objetivo superar as visões demasiado cristalizadas da história da filosofia, e ainda reinantes em certas paragens do meio acadêmico, encarando o desafio que consiste, como escreve, "em penetrar criticamente a densa camada de cultura que se interpõe entre nós e os versos de Parmênides". Como o jovem companheiro das aurigas imortais descrito em seu prólogo pelo poeta-filósofo, Marcelo se deixou arrebatar pelas aladas palavras do poema e emprestou seu pensamento e sua voz para nos arrastar da morada da noite à morada do dia, trazendo novas luzes à interpretação do pensamento do Eleata. Marcelo tinha a convicção de que "a história da cultura é uma espiral em movimento constante" na qual o mundo antigo vai se "revelando, inevitavelmente, como permanente recriação, reconstrução." (Memorial). Este, podemos dizer, é também o movimento que caracterizou o seu movimento de investigação ao se debruçar sobre o legado da Antiguidade grega e, particularmente, das filosofias préplatônica e platônica.

As questões que orientavam sua pesquisa se interessavam sobretudo pelo sentido mesmo da pergunta pelo ser, subjacente à qual se encontra aquela ainda mais eloquente pela relação entre ser e linguagem: “em que medida... se exigem ou se excluem?”, se perguntava Marcelo.

Sua frequentação da poesia filosófica parmenidiana estava de certo modo preparando o caminho que viria a se descortinar mais tarde como aquele de sua tese de doutorado: a discussão do diálogo em que, já na primeira cena, Platão nos apresenta o estrangeiro de Eleia entregue ao elenchos das teses do "pai". Ao considerar a apropriação platônica do pensamento eleata, Marcelo torna explícita a sua intenção no estudo do Sofista de Platão: "queremos resgatar a reverência com que o velho eleata é abordado, no momento mesmo em que é aparentemente refutado" (O caminho poético de Parmênides, p. 14. Grifo nosso.).

O seu estudo de Parmênides constituiu, assim, o marco fundador das suas pesquisas futuras, seja da sua tese de doutorado, seja da pesquisa que se desenrolou a partir dela, a saber, o tema do ser e do parecer.

Minha preocupação com o tema do aparecer e da aparência remonta ao meu trabalho de Mestrado, no qual, ao estudar o poema de Parmênides de Eleia, me deparei com a intrigante formulação do programa de pesquisa que a deusa propõe ao jovem em busca de saber. Em poucos versos, o pai filosófico de Platão formula, pela primeira vez, um dos problemas centrais da filosofia ocidental desde então, ao associar à busca da 'verdade' o estudo daquilo que 'parece ser'. Tanto o 'ser verdadeiro' como o 'parecer ser' afirmam-se, então, como objetos dignos de estudo. ${ }^{3}$

\footnotetext{
${ }^{3}$ Marcelo tem aqui presente os versos seguintes do poema: "é preciso que de tudo te instruas, do âmago inabalável da verdade bem redonda, e de opiniões de mortais, em que não há fé verdadeira. No entanto também isto aprenderás, como as aparências deviam validamente ser, tudo por tudo atravessando". (Simplício, De caelo 557.25-558. 2 ed. Heiberg. Parmênides DK28B I 28-32. Trad. Cavalcante de Souza).
} 
Para Marcelo, o final do fragmento 1 de Parmênides, "no entanto também isto aprenderás, como as aparências deviam validamente ser, tudo por tudo atravessando", constitui o que seria no seu entender "o primeiro programa de pesquisa da filosofia ocidental":

Esta passagem integra o que poderíamos chamar de o primeiro programa de pesquisa da filosofia ocidental: é preciso se instruir sobre a verdade e sobre as opiniões (dóxai), e aprender (aprenderás - mathésai) sobre as aparências; objeto de grande polêmica interpretativa, o texto não só considera "as coisas que aparecem" (tà dokoûnta) como fazendo parte do que é, mas também, ao reconhecer sua presença universal (pantòs pánta), confere-lhes dignidade de objeto de pesquisa.

A subsistência de seu interesse pelo problema enunciado por Parmênides o acompanharia, ainda que de modo menos direto, ao longo da preparação de sua tese de doutorado, contemplando outros aspectos e nuances, mas voltaria ao primeiro plano nos últimos anos de sua atividade investigativa. A seu ver, a polarização 'ser' e 'não ser' não recobre aquela entre 'ser' e 'aparecer', e não haveria em Parmênides, como pretende boa parte da crítica contemporânea, uma nítida consciência da oposição "sensível - inteligível". A este respeito ele escreve em seu Memorial:

... tanto o que é referido como aparecer, como o que é dito 'ser' constituem uma experiência integrada de sensação e intelecção. O que é criticável no 'aparecer' é a imediatidade da experiência que ele implica, e não propriamente uma insuficiência ontológica. O que é objeto de censura, por parte da deusa, é a valoração do imediato às custas da mediação pela reflexão, principalmente na medida em que, enquanto valor, as 'coisas que aparecem' e a 'opinião' tornam-se aquilo que dirige os mortais em suas ações, "pois o imediato (amekhanie - impotência, falta de recurso) em seus peitos dirige pensamento errante". "O que é”, para Parmênides, encampa tanto o físico quanto o lógico (para falar em termos correntes para nós), portanto, não encontramos uma cisão metafísica entre substâncias opostas, mas, antes, uma reflexão poética que figura a experiência do conhecimento enquanto encruzilhada de caminhos, experiência que está plenamente inserida na cidade enquanto práxis política.

Não é estranho, portanto, que após seus anos de estudo e de pesquisa em torno do pensamento do pensador Eleata, Marcelo viesse a dirigir seu interesse à filosofia de Platão, no qual reconhece um desenvolvimento natural das preocupações e do problema trazido à luz pela reflexão de Parmênides. A seu ver, 
Platão retoma Parmênides em perspectiva crítica e dialetiza o que nele é experiência compacta. Ele distende as tensões do poema na direção do diálogo, ou seja, da sua própria dialética. O objeto da dóxa (República V), aquilo que aparece, não é menos real, no sentido de existência, como mostra claramente Vlastos. Não se trata de graus de existência, mas de graus de determinação ontológica, de níveis de inteligibilidade e de cognoscibilidade.

'Aquilo que aparece', pela sua imediatidade, não contém sua própria crítica, não é capaz de dar razão de si mesmo, não nos fornece, por si só, o critério de sua veracidade. 'Aquilo que aparece' tem que ser submetido à mediação progressiva do perguntar / responder para que se possa estabelecer, com relação a ele, 'o que é' e 'o que não é'. A aparência não constitui um "mundo"; ela é avaliada enquanto um momento da experiência do conhecimento; sendo objeto de diferentes valorações, ela pode ser tomada como valendo mais do que vale, como sendo o que ela não é. Donde a necessidade de uma apropriação sempre crítica da imediatidade do aparecer.

Para encerrar esta breve apresentação em que pretendemos dar voz ao próprio Marcelo na tentativa de compreender este momento inaugural de sua atividade nas sendas da Filosofia, gostaríamos de evocar três aspectos por ele mesmo apontados como as conclusões desta sua "viagem" conduzida pelo auriga Parmênides. Uma primeira conclusão se compraz no reconhecimento da palavra como "instância reveladora" tanto da identidade quanto da diferença, e de que a relação entre as coisas que são e o ser se manifesta tanto na ausência quanto na presença, não sendo esta relação determinada nem pela fixidez nem pela relatividade absoluta:

Essa relação não é nem de fixidez nem de absoluta relatividade, os seres se fundam no ser ao modo da ausência-presença. O ser não se confunde com os seres, o que não impede de se relacionar com eles, fundando-os firmemente. À medida que diz os seres, na sua pluralidade e variedade, a dóxa é um modo da presença, é no nomear que as coisas aparecem tal como são. ${ }^{4}$

Uma segunda conclusão consiste em ver no "esquema mítico-poético dos caminhos" não um dualismo, mas justamente o "que impede sua dicotomização", a mera contraposição de "registros ou linguagens diferentes":

A ambiguidade essencial do ser se desdobra poeticamente como cruzamento entre caminhos, esquema mítico cuja irredutibilidade preserva a força presentificadora da palavra. É justamente isso que dá ao poema de Parmênides seu caráter singular, único. O discursivo apenas

\footnotetext{
${ }^{4}$ Marques, M. P. O caminho poético de Parmênides. Coleção "Filosofia”. São Paulo: Edições Loyola, 1990. p. 110.
} 
desponta, descolando-se do mítico, mas não prescindindo dele. O mítico excede, transborda do discursivo: o poeta-filósofo busca o fundamento do seu discurso em divindades que, de dentro desse discurso mesmo, o ligam, o amarram, determinam seu fundamento último, o ser.

E, enfim, a convicção de que a filosofia é caminho, "caminho poético", que mesmo quando já trilhado permanece sempre por ser ainda e ainda percorrido, devendo sempre "ser refeito", na experiência que resulta do entrelaçamento de um dizer que presentifica e que argumenta, pois como pensava Marcelo, "a filosofia, tal como aprendemos com Parmênides, é tanto um como o outro inseparavelmente". ${ }^{5}$ Os versos de José Lorite Mena citados por Marcelo ao final do seu caminho poético pelo pensamento de Parmênides sintetizam o espírito que o animava

\section{L'bomme qui sait est celui qui par son désir dresse son éthos dans \\ l'attente de l'inconnu: \\ il a fait le choix de \\ l'inhabituel. 6}

Neste dossiê publicamos alguns dos textos que foram apresentados por ocasião do VI Simpósio Internacional de Estudos Antigos, evento promovido pelo grupo Filosofia Antiga da UFMG, que no ano de 2017, um ano após a morte de Marcelo, foi consagrado a celebrar a sua memória, reunindo em torno do tema da philia na Antiguidade, amigos e colegas pelos quais ele nutria admiração e com os quais colaborou de diferentes maneiras ao longo de sua atividade acadêmica.

\footnotetext{
${ }^{5}$ Marques, M. P. O caminho poético de Parmênides. Coleção “Filosofia”. São Paulo: Edições Loyola, 1990. p. 111.

${ }^{6}$ Mena, José Lorite. Parménide: la Parole entre la Vérité et le Soupçon. Revue de Métaphysique et de Morale, v. 83, n. 3, p. 289-307, 1978.
} 